\title{
Identification of a Major Sialoprotein in the Glycocalyx of Human Visceral Glomerular Epithelial Cells
}

\author{
D. Kerjaschki, * H. Poczewski, " G. Dekan," R. Horvat, * E. Balzar, * N. Kraft, $\ddagger$ and R. C. Atkinsł \\ ${ }^{*}$ Departments for Pathological Anatomy and Pediatrics, University of Vienna, Vienna, A-1090 Austria; and \\ $\ddagger$ Department of Nephrology, Prince Henry Hospital, Monash University, Melbourne 3004, Australia
}

\begin{abstract}
Glomerular visceral epithelial cells are endowed with a sialic acid-rich surface coat (the "glomerular epithelial polyanion"), which in rat tissue contains the sialoprotein podocalyxin. We have identified a major membrane sialoprotein in human glomeruli that is similar to rat podocalyxin in its sialic acid-dependent binding of wheat germ agglutinin and in its localization on the surface of glomerular epithelial and endothelial cells, as shown by immunoelectron microscopy, using the monoclonal antibody PHM5. Differences in the sialoproteins of the two species are indicated by the discrepancy of their apparent molecular weights in sodium dodecyl sulfate gels, by the lack of cross reactivity of their specific antibodies, and by the lack of homology of their proteolytic peptide maps. It is therefore possible that the human glomerular sialoprotein and rat podocalyxin are evolutionarily distinct, but have similar functions.
\end{abstract}

\section{Introduction}

Glomeruli of human and animal kidneys are rich in sialic acid, as indicated by histochemical staining with cationic dyes, such as colloidal iron and alcian blue (1-3), and by labeling with lectins with specificity for sialic acid $(4,5)$. The anionic groups responsible for these staining properties have been called collectively the "glomerular epithelial polyanion." They are of interest because in glomerular diseases, especially in human minimal change nephrosis (6), and in a corresponding experimental rat model, puromycin-aminonucleoside nephrosis (7), the staining for the glomerular polyanion is reduced or lost. This is paralleled by the deformation of the glomerular epithelial cells (podocytes), and the onset of proteinuria. It was concluded that the glomerular polyanion is associated with the complex structure of glomerular epithelial cells, and with the regulation of correct glomerular filtration.

We have recently identified and isolated a sialoprotein with an apparent $M_{\mathrm{r}}$ of $140 \mathrm{kD}$ from rat kidney glomeruli and we have shown that it is the major sialoglycoprotein in the glomerular epithelial surface coat. Because this molecule was found in the glycocalyx of podocytes we have called it "podocalyxin" (8).

In this study we define a sialoprotein in human glomeruli that shares several properties with rat podocalyxin but that is not homologous by peptide mapping or by immunochemistry.

Received for publication 13 August 1985 and in revised form 16 June 1986.

J. Clin. Invest.

(C) The American Society for Clinical Investigation, Inc.

$0021-9738 / 86 / 11 / 1142 / 08 \quad \$ 1.00$

Volume 78, November 1986, 1142-1149

\section{Methods}

Materials. Sodium dodecyl sulfate (SDS), acrylamide, bisacrylamide, "Stains All," and nitrocellulose membrane were from Bio-Rad Laboratories (Richmond, CA). Wheat-germ agglutinin (WGA), ${ }^{1}$ chloramin $\mathrm{T}$, neuraminidase from Clostridium perfringens (Typ X), pepstatin, antipain, leupeptin, diisopropyl fluorophosphate, benzamidine, and hemoglobin were from Sigma Chemical Co. (St. Louis, MO). $N$-Glycanase was obtained from Genzyme (Boston, MA). Fluorescein isothiocyanateconjugated goat anti-mouse IgG was from Cappell Laboratories (Cochranville, PA). Sheep anti-mouse Fab-horseradish peroxidase conjugate was from the Institut Pasteur (Marnes la Coquette, France). ${ }^{125}$ I was obtained from Amersham International (Buckinghamshire, England). Staphylococcal $\mathrm{V}_{\mathbf{8}}$ protease, $\alpha$-chymotrypsin, and subtilisin were gifts from Dr. H. Herrmann (Department of Biochemistry, University of Vienna, Austria).

Isolation and extraction of glomeruli. Kidneys of two patients (males, 46 and $58 \mathrm{yr}$ old) were surgically removed because of hypernephroid carcinomas on one pole. The tumors had diameters of $>4 \mathrm{~cm}$ and did not penetrate into the renal pelvis or blood vessels. The kidney cortices (distant from the tumors) were dissected immediately and immersed into ice-cold minimal essential medium containing a cocktail of protease inhibitors $(10 \mu \mathrm{g} / \mathrm{ml}$ of pepstatin, antipain, and leupeptin, $10 \mathrm{mM}$ diisopropyl fluorophosphate, and $10 \mathrm{mM}$ benzamidine). A small piece was fixed in $2.5 \%$ glutaraldehyde in $100 \mathrm{mM}$ cacodylate buffer (pH 7.3) and embedded in Epon 812 for routine electromicroscopy, and a major specimen was embedded in paraffin for pathological routine diagnosis. Both methods revealed normal morphology of the kidney and the glomeruli. Most of the material was minced with razor blades and pressed through Teflon sieves of decreasing pore size $(250,150$, and $70 \mu \mathrm{m})$ at $4^{\circ} \mathrm{C}$. The glomeruli were collected from the $70-\mu \mathrm{m}$ screen and pelleted in a microfuge tube by 1-min centrifugation in a Microfuge B (Beckman Instruments Inc., Fullerton, CA).

Isolated glomeruli (derived from $\sim 10 \mathrm{~g}$ of cortical tissue) were lysed in $3 \mathrm{ml}$ of $2 \times$ SDS sample buffer (7.2\% SDS, $16 \mathrm{mmol}$ dithiothreitol, $16 \mathrm{mmol}$ EDTA, $20 \%$ glycerol, and $100 \mathrm{mmol}$ Tris-phosphate buffer [pH 6.8]), and boiled for 3-5 min. The samples were then centrifuged for $5 \mathrm{~min}$ at $10,000 \mathrm{~g}$ in a Microfuge B, and the supernatants were stored at $-20^{\circ} \mathrm{C}$.

Glomeruli from rat kidneys as controls were isolated and solubilized as described in detail before (8).

SDS PAGE and staining of gels. Glomerular lysates were loaded onto 5-10\% gradient SDS gels as described previously (8). The gels were stained and fixed in 0.5\% Coomassie Blue in 50\% methanol and $7 \%$ acetic acid, and destained in $25 \%$ methanol and $7 \%$ acetic acid. Some gels were stained with Stains All as described previously (8). For direct comparison of the mobility of the stained bands in human glomerular lysates, and as a positive control for the staining procedure, lysates from isolated rat glomeruli were loaded in slots adjacent to the human material. For calibration, a kit of high molecular mass standards (Bio-Rad Laboratories) was used.

Transfer onto nitrocellulose. The glomerular proteins were transferred from SDS gels onto nitrocellulose as described previously (8). The trans-

1. Abbreviations used in this paper: $\mathrm{DAB}$, diaminobenzidine; PNA, peanut agglutinin; WGA, wheat germ agglutinin. 
ferred protein bands were stained with $0.5 \%$ Ponceau $\mathrm{S}$, destained in $10 \%$ acetic acid, and photographed.

Lectin overlays. Strips of the nitrocellulose transfers with rat and human glomerular proteins were overlaid with ${ }^{125} \mathrm{I}-\mathrm{WGA}$ as described in detail previously (8), and autoradiographed on Kodak XO-mat X-ray film with a Cronex (DuPont Instruments, Wilmington, DE) intensifying screen at $-70^{\circ} \mathrm{C}$ for 12 to $32 \mathrm{~h}$. Some nitrocellulose strips were predigested with neuraminidase $(0.05 \mathrm{U} / \mathrm{ml})$ for $12 \mathrm{~h}$ at $37^{\circ} \mathrm{C}$, and subsequently incubated either in ${ }^{125} \mathrm{I}-\mathrm{WGA}$, or in ${ }^{125} \mathrm{I}$-peanut agglutinin (PNA) (8), and processed as above.

Monoclonal antibodies. Monoclonal antibodies were raised by immunization of mice with isolated human glomeruli as described previously $(9,10)$. IgG of the clone PHM5 was recovered from ascites of mice by precipitation with ammonium sulfate.

Immuneoverlay. Strips of nitrocellulose transfers with the human glomerular proteins were first incubated in Tris-buffered saline $(\mathrm{pH} 7.5)$ containing $40 \%$ human $\mathrm{AB}-$ serum for $1 \mathrm{~h}$. Then the strips were incubated in the same buffer with $25 \mu \mathrm{g} / \mathrm{ml}$ of monoclonal PHM5 IgG, and processed by the peroxidase-anti-peroxidase-complex method for visualization of the antigens with 4-chloro-1-naphtol in Tris-buffered saline.

Radioiodination of proteins in nitrocellulose. Proteins of rat and human glomeruli were separated on 5-10\% gradient SDS gels, and transferred onto nitrocellulose. The positions of rat podocalyxin and the human 165- and 170-kD bands were determined by immuneoverlaying. Corresponding bands (that contain $\sim 50 \mathrm{ng}$ protein as assessed by the intensity of the immunostaining reaction on overlays) were cut out from adjacent lanes of the nitrocellulose sheets, and labeled directly with 0.5 $\mathrm{mCi}$ of ${ }^{125} \mathrm{I}$ by the chloramin $\mathrm{T}$ method (11). The efficiency of labeling was checked by eluting the labeled proteins from small fragments of the paper strips by boiling in 1\% SDS buffer for 2 min, counting in a gammacounter, and by further analysis of the SDS eluate by electrophoresis on a 7\% SDS gel, followed by fixation/staining, destaining, and exposure for autoradiography as described above.

Digestion of the 170-kD band with neuraminidase and $N$-glycosidase $F$ (N-glycanase). Nitrocellulose strips containing the ${ }^{125}$ I-labeled human 170-kD molecule were incubated in 1\% hemoglobin in PBS for $30 \mathrm{~min}$, washed five times in PBS, and blotted dry. Pieces of the strips, containing $5,000 \mathrm{cpm}$ were then incubated in 0.01 and $0.1 \mathrm{U}$ neuraminidase in 100 $\mu 150 \mathrm{mM}$ acetate buffer (pH 5.5) containing the protease inhibitor cocktail described above, and $10 \mathrm{mM} \mathrm{CaCl} 2$ for $12 \mathrm{~h}$ at $37^{\circ} \mathrm{C}$. After washing in phosphate-buffered saline (PBS), the strips were boiled for $5 \mathrm{~min}$ in SDS sample buffer. The released proteins were separated by 7\% SDS PAGE and visualized by autoradiography as described above.

For digestion with $\mathrm{N}$-glycanase, five hemoglobin-quenched nitrocellulose strips of the $170-\mathrm{kD}$ protein containing $2,500 \mathrm{cpm}$ each were boiled for $10 \mathrm{~min}$ in $20 \mu \mathrm{l}$ of $0.5 \%$ SDS. After cooling of the released material to $20^{\circ} \mathrm{C}, 20 \mu \mathrm{l} 0.3 \mathrm{M}$ phosphate buffer (pH 8.6) $3 \mu \mathrm{l}$ of $100 \mathrm{mM} \mathrm{1,10}$ phenanthroline hydrate (in methanol), and $10 \mu 17.5 \%$ Nonidet P-40 were added. $0.1,1,10$, and $25 \mathrm{U}$ of $\mathrm{N}$-glycanase were added, and one sample received no enzyme. The vials were incubated at $37^{\circ} \mathrm{C}$ for $12 \mathrm{~h}$. Then $10 \mu \mathrm{l} 10 \%$ SDS and $30 \mu \mathrm{l} 2 \times$ SDS sample buffer were added and boiled for $5 \mathrm{~min}$. The samples were analyzed on 7\% SDS gels that were stained, dryed, and autoradiographed.

Peptide mapping. The ${ }^{125} \mathrm{I}$-labeled proteins were released from the nitrocellulose strips by incubation with $50 \mu \mathrm{l} 1 \%$ SDS, $20 \mathrm{mM}$ Tris $\mathrm{HCl}$ buffer (pH 6.8), and $10 \%$ glycerol for $10 \mathrm{~min}$ at $95^{\circ} \mathrm{C}$. The SDS lysate was then loaded into the slots of a $12 \%$ SDS gel, and overlaid with $1 \mu \mathrm{g}$ staphylococcal $V_{8}$ protease (12). The enzyme was dissolved in $15 \mu \mathrm{l}$ running buffer with $10 \%$ glycerol. The mixture was electrophoresed with $1 \mathrm{~W}$ constant power through a $12 \%$ SDS gel, and stained and fixed, dryed, and exposed for autoradiography as described above.

For further comparison, several fragments of the $\mathrm{V}_{8}$-cleaved molecules were excised from the dried gels after autoradiography; swollen in 100 $\mu \mathrm{l} 1 \%$ SDS, and subjected to a second round of digestion with subtilisin (10 $\mu \mathrm{g} / \mathrm{slot}$, dissolved in running buffer with $10 \%$ glycerol) (13). The digests were separated on $12 \%$ SDS gels that were run and processed as described above.

Immunofluorescence. Cryostat sections ( $4 \mu \mathrm{m})$ were prepared from human kidneys with hypernephroid carcinomas, or from kidney biopsy specimens. The sections were fixed for $1 \mathrm{~min}$ in acetone at $-20^{\circ} \mathrm{C}$, washed in PBS, incubated in $20 \mu \mathrm{g} / \mathrm{ml}$ PHM5-IgG in PBS, and fluorescein isothiocyanate-conjugated goat anti-mouse IgG, and examined in a Zeiss Photomicroscope I.

Immunoperoxidase. Pieces of kidney biopsy cylinders (from patients with normal glomerular morphology as found by subsequent routine diagnostical examination by electron microscopy) were fixed in periodatelysine-paraformaldehyde fixative for $6 \mathrm{~h}$ at $20^{\circ} \mathrm{C}$, and processed for immunoperoxidase as described in detail previously $(8,14)$. Briefly, cryostat sections were incubated first in $20 \mu \mathrm{g} / \mathrm{ml}$ PHM5-IgG, washed, then incubated with sheep anti-mouse Fab fragment coupled to horseradish peroxidase, followed by the diaminobenzidine (DAB) reaction and postfixation in ferrocyanide-osmium and embedding in Epon 812. Ultrathin sections were stained with lead citrate and examined in a Zeiss EM9 electron microscope.

As control, cryostat sections were incubated with an irrelevant monoclonal mouse IgG (directed against rat gp330, 14), and processed as described above.

\section{Results}

Identification of sialoproteins in human glomeruli by staining and lectin-binding. When the proteins of SDS extracts of rat and human glomeruli are stained with Coomassie Blue in SDS gels or with Ponceau $S$ in nitrocellulose transfers (Fig. 1, lanes $B$ and

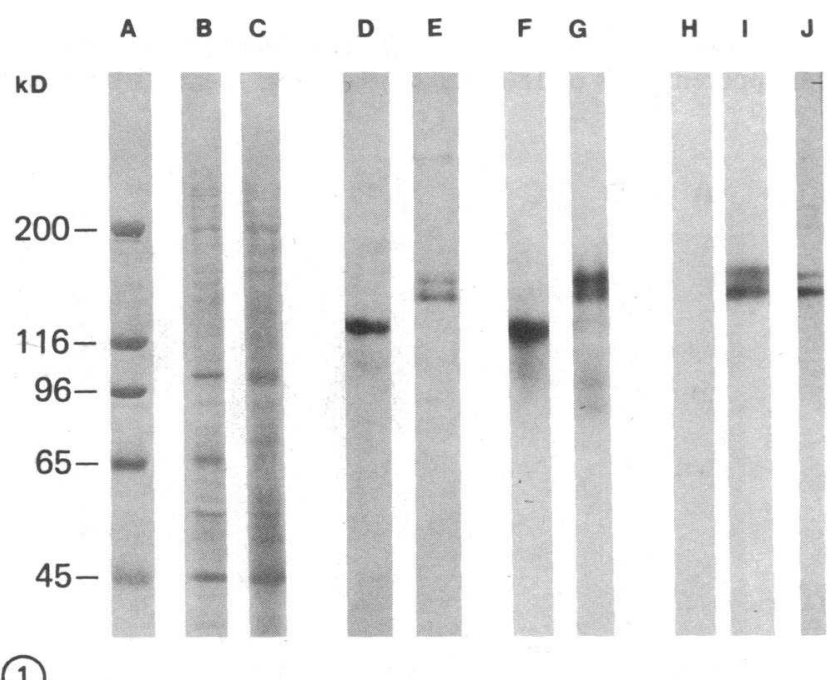

Figure 1. Comparison of rat podocalyxin and the human glomerular sialoprotein. Isolated glomeruli from rats and humans were lysed in SDS-containing buffer. The solubilized proteins were separated by 5$10 \%$ gradient SDS PAGE, transferred onto nitrocellulose, and stained with Ponceau S. Lysates from rat (lane $B$ ) and human (lane $C$ ) glomeruli share several bands of similar mobility. Stains All, which is specific for negatively charged proteins, labels selectively rat podocalyxin (lane $D$ ) with an apparent $M_{\mathrm{r}}$ of $140 \mathrm{kD}$, whereas two closely co-migrating bands with apparent $M_{\mathrm{r}} 165-170 \mathrm{kD}$ are stained in human lysates (lane $E$ ). In nitrocellulose overlays, ${ }^{125} \mathrm{I}$-WGA binds to rat podocalyxin (lane $F$ ), and to the two Stains All-positive bands in human glomerular extract (lane $G$ ). When human glomerular extracts are digested with neuraminidase $(0.05 \mathrm{U} / \mathrm{ml}, 12 \mathrm{~h})$, and subsequently overlaid with ${ }^{125} \mathrm{I}-\mathrm{WGA}$, no binding is observed (lane $H$ ). By contrast, the human 165-170-kD sialoprotein doublet is now labeled on newly exposed ${ }^{125}$ I-PNA-binding sites (lane $I$ ) that were not accessible before neuraminidase digestion. Lane $J$, the monoclonal antibody PHM5 selectively labels the human 165-170-kD doublet by an indirect immunoperoxidase procedure. Lane $A$ contains molecular mass standards. 
C), 8-10 major bands with various $M_{\mathrm{r}}$ are visible. Several major proteins with identical electrophoretic mobility are shared by both species (e.g., bands with apparent $M_{\mathrm{r}}$ of 40, 100, and 200 kD), (Fig. 1, lanes $B$ and $C$ ).

The carbocyanide dye Stains All, an indicator for highly negatively charged residues (15), selectively stains metachromatically a prominent $140-\mathrm{kD}$ band in rat glomerular lysates (Fig. 1, lane D), which is characteristic for the sialoprotein podocalyxin (8). In contrast, a doublet of bands with apparent $M_{\mathrm{r}}$ of 165 and $170 \mathrm{kD}$ are selectively stained in human glomerular lysates (Fig. 1, lane $E$ ). In addition, a band of $<200 \mathrm{kD}$, whose identity is unknown, is weakly stained.

In nitrocellulose transfers of rat glomerular proteins, ${ }^{125} \mathrm{I}$ WGA binds to podocalyxin (Fig. 1, lane $F$ ), and this labeling was previously found to be abolished by predigestion with neuraminidase (8). In transfers of human glomerular proteins, the lectin most prominently binds to the $165-170-\mathrm{kD}$ doublet of bands (Fig. 1, lane $G$ ). As with rat podocalyxin, the binding of WGA to the doublet in human glomerular lysates is sensitive to neuraminidase (Fig. 1, lane $H$ ), and ${ }^{125}$ I-PNA-binding sites are exposed on these molecules after digestion (Fig. 1, lane $I$ ).

Comparison of rat podocalyxin and the human 165-170-kD glycoproteins by peptide mapping. When the iodinated sialoproteins are released from the nitrocellulose by SDS and are rerun on SDS gels, rat podocalyxin and human $170-\mathrm{kD}$ glycoprotein show the same mobility as the unlabeled original molecules (Fig. 2 , lanes $A$ and $C$ ). The $165-\mathrm{kD}$ band is split into two components with apparent $M_{\mathrm{r}}$ 's of 180 and $165 \mathrm{kD}$ (Fig. 2, lane $B$ ), which show almost identical peptide maps after cleavage with $V_{8}$ protease and chymotrypsin (not shown).

Digestion of the human $170-\mathrm{kD}$ glycoprotein by $\mathrm{V}_{\mathbf{8}}$ protease generates five major peptides with $M_{\mathrm{r}} \mathrm{s}$ of $80,60,25,18$, and 16 $\mathrm{kD}$ (Fig. 2, lane $D$ ). An almost identical peptide map is observed for the human $165-\mathrm{kD}$ molecule (Fig. 2, lane $E$ ). This indicates extensive homology of the two bands. Chymotrypsin also generates peptides of similar electrophoretic mobility (not shown).

Rat podocalyxin is cleaved by $\mathrm{V}_{8}$-protease only into a major 80-kD and a minor $15-\mathrm{kD}$ fragment (Fig. 2, lane $F$ ). When the 80-kD V $\mathrm{V}_{8}$-peptides of the human $170-\mathrm{kD}$ molecule and of rat podocalyxin are redigested with subtilisin, the pattern of the major peptides is dissimilar. Only four minor bands out of 12 rat podocalyxin fragments show the same electrophoretic mobility as the fragments obtained from the human $80-\mathrm{kD}$ peptide (Fig. 2, lanes $G$ and $H$ ) after long times of exposure of the autoradiograms. This is because the relative amounts of the shared bands are also quite different. Similar results are obtained when the uncleaved rat and human molecules were digested with subtilisin of $\alpha$-chymotrypsin (not shown).

Digestion of the 170-kD protein with neuraminidase and $N$ glycanase. When the ${ }^{125} \mathrm{I}$-labeled $170-\mathrm{kD}$ band is digested with $0.01 \mathrm{U}$ of neuraminidase, a band with higher (apparent $M_{\mathrm{r}} 150$ kD) and one with lower (apparent $M_{\mathrm{r}} 180 \mathrm{kD}$ ) electrophoretic mobility than the original $170-\mathrm{kD}$ band appear (Fig. 3, lane $B$ ). After digestion with $0.1 \mathrm{U}$ of neuraminidase, only the $150-\mathrm{kD}$ band is visible in autoradiograms (Fig. 3, lane $C$ ).

Removal of $\mathrm{N}$-linked oligosaccharide chains with $\mathrm{N}$-glycan-
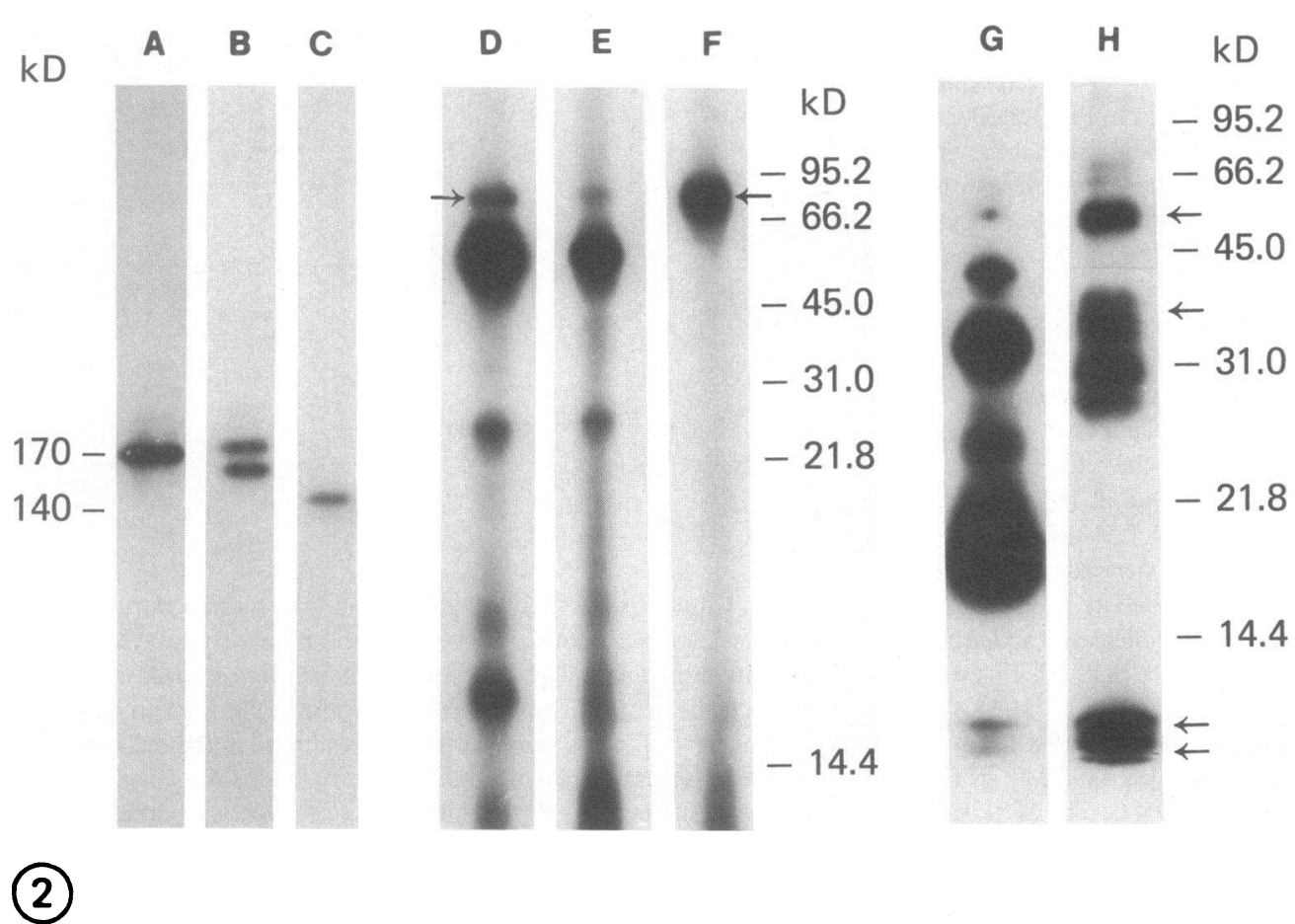

Figure 2. Comparison of radioiodinated intact sialoproteins (lanes $A-C)$ and the proteolytic peptides (lanes $D-H$ ) of rat podocalyxin and the human glomerular sialoprotein. The human 165 and $170-\mathrm{kD}$ bands and rat podocalyxin were excised separately from nitrocellulose transfers and labeled individually with ${ }^{125} \mathrm{I}$ by the chloramin $\mathrm{T}$ procedure while immobilized on the nitrocellulose membrane. The radioactive proteins were then eluted from the nitrocellulose strips in $1 \%$ SDS, and were electrophoresed on a 7\% SDS gel. After fixation/ staining of the gel and drying, the bands were visualized by autoradiography. Lane $A$ is the rerun ${ }^{125}$ I-labeled 170-kD band, and lane $B$ the $165-\mathrm{kD}$ component of the human sialoprotein. Lane $C$ is ${ }^{125}$ I-labeled rat podocalyxin. The excised labeled $165-\mathrm{kD}$ band in lane $B$ is split into a 180 - and a $165-\mathrm{kD}$ band, probably due to

modification of the molecule by the labeling procedure. The time of exposure for autoradiography in lanes $A-C$ was 2 min. Lanes $D-F$, peptide maps generated on $12 \%$ SDS-gels by digestion with $\mathrm{V}_{8}$ protease $(1 \mu \mathrm{g} / \mathrm{slot})$ from ${ }^{125} \mathrm{I}$-labeled human $170-\mathrm{kD}$ (lane $\left.D\right)$ and $165-\mathrm{kD}$ (lane $E$ ) glycoprotein, and rat podocalyxin (lane $F$ ). Whereas the two human molecules show almost identical maps, rat podocalyxin only shares a 80-kD fragment with the human molecule (arrow) (exposure time, 90 min). Lanes $G$ and $H$, the 80-kD peptides that are shared in the $\mathrm{V}_{8}$ peptide maps by rat and human sialoproteins were excised from the dried gels and subjected to another round of digestion with subtilisin ( $5 \mu \mathrm{g} / \mathrm{slot})$, and separation of the peptides on a $12 \%$ SDS gel. Four bands (arrows) of the two peptide patterns show similar mobility, although their quantitative differences are significant. Most of the peptides are different in their electrophoretic mobility. (exposure time, $4 \mathrm{~d}$ ). 


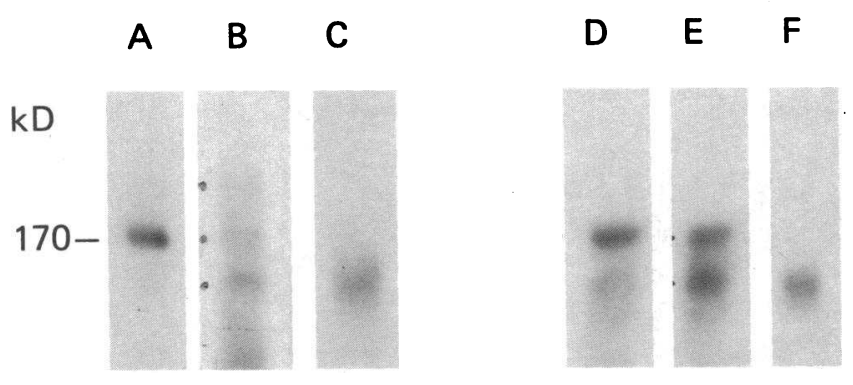

(3)

Figure 3. Autoradiograms of the ${ }^{125}$ I-labeled $170-\mathrm{kD}$ band (lane $A$ ) after digestion with neuraminidase (lanes $B$ and $C$ ) and $N$-glycanase (lanes $D-F$ ). Treatment with $0.01 \mathrm{U}$ of neuraminidase generates a band with an apparent $M_{\mathrm{r}}$ of $150 \mathrm{kD}$ and one with an apparent $M_{\mathrm{r}}$ of $180 \mathrm{kd}$ (lane $B$, points). The mobility of the latter band could be due to incomplete desialylation, which is known to reduce the intrinsic negative charge of molecules and thus slow down their mobility in SDS gels. Digestion with $0.1 \mathrm{U}$ neuraminidase generates only the 150 $\mathrm{kD}$ band (lane $C$ ). Digestion with $\mathrm{N}$-glycanase in three concentrations $(0.1 \mathrm{U}$ in lane $D, 1 \mathrm{U}$ in lane $E$, and $10 \mathrm{U}$ in lane $F$ ) also results in a band with an electrophoretic mobility corresponding to an $M_{\mathrm{r}}$ of $150 \mathrm{kD}$.

ase generates a band with an apparent $M_{\mathrm{r}}$ of $150 \mathrm{kD}$ (Fig. 3, lanes $D-F$ ), i.e., a similar mobility as the $150-\mathrm{kD}$ band obtained by neuraminidase digestion.

Determination of the specificity of monoclonal $\mathrm{IgG}$ from clone PHM5. When nitrocellulose strips containing the entire repertoire of solubilized proteins from human glomeruli are overlaid with PHM5-monoclonal IgG, the 165-170-kD bands are selectively labeled (Fig. 1, lane $J$ ). After overlaying with monoclonal anti-rat gp330 IgG (14) as a control, no signal was obtained in human glomerular lysates (not shown).

Localization of the human glomerular sialoprotein by immunocytochemistry with PHM5 IgG. Intense staining of the glomerular epithelial cells is found by indirect immunofluorescence on cryostat sections of normal human kidneys (Fig. 4), as described previously for monoclonal PHM5-IgG (9). Monoclonal PHM5-IgG does not bind to rat kidney, and affinity-purified rabbit anti-rat podocalyxin IgG gives no signal in human kidney sections (not shown).

By immunoelectron microscopy, using an indirect immunoperoxidase technique $(8,14)$, a thick layer of DAB reaction product is observed on the surfaces of visceral glomerular epithelial cells (Figs. 5 and 6), but not at their base. Also, the endothelial cells of glomeruli are stained, as seen particularly well in grazing sections (Fig. 6). DAB reaction product is found on the luminal membrane of all endothelial cells in interstitial capillaries (Fig. 7) and in blood vessels of larger caliber. Mesangial and tubular epithelial cells are consistently negative. Cryostat sections that were incubated with monoclonal anti-gp330 IgG as first antibody as a control showed no glomerular or endothelial staining.

\section{Discussion}

In this study we have identified a sialoprotein from human glomeruli that appears as a doublet of bands with apparent $M_{\mathrm{r}} s$ of 165 and $170 \mathrm{kD}$ by SDS PAGE. This molecule shares several properties with rat podocalyxin, which is the major silaloprotein in rat glomeruli and the main component of the glomerular epithelial polyanion (8). Immunochemical and structural data indicate, however, that the human glomerular sialoprotein is chemically distinct from rat podocalyxin.

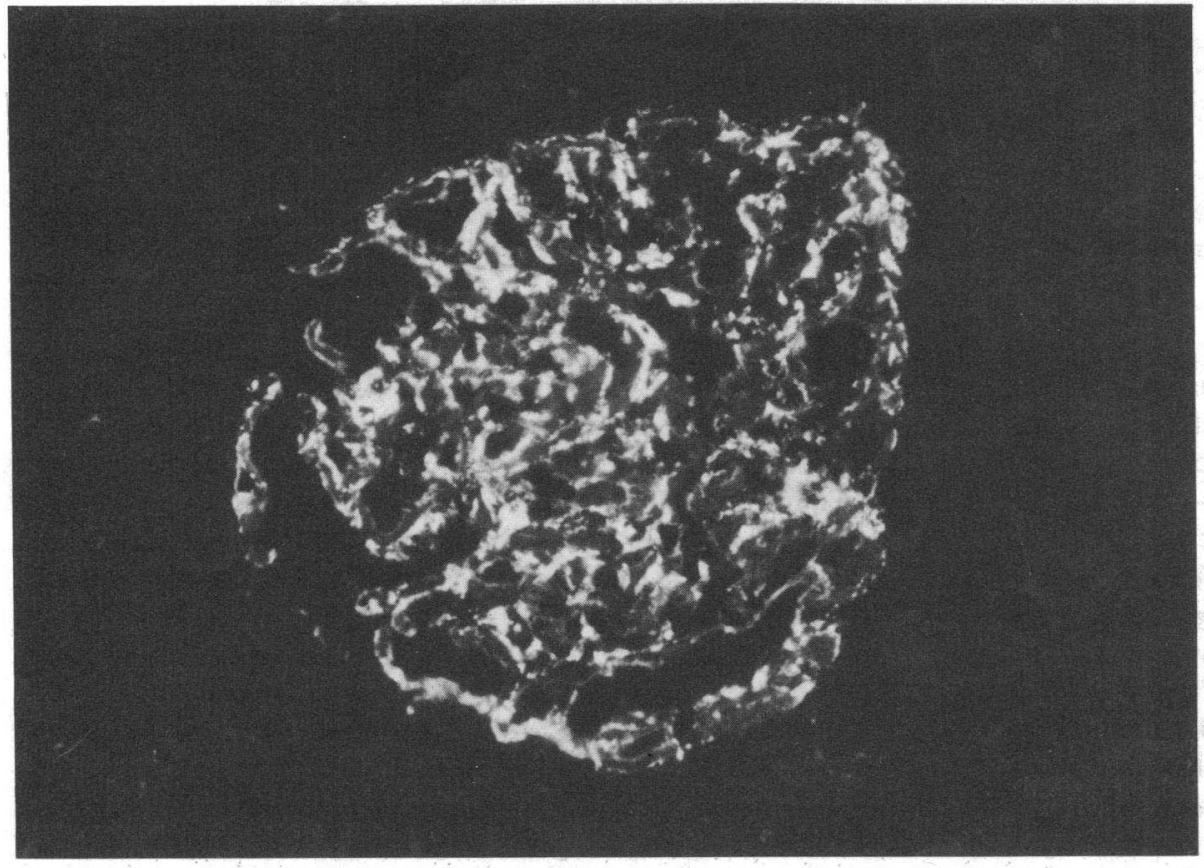

(4)
Figure 4. Localization of the human 165$170 \mathrm{kD}$ sialoprotein by indirect immunofluorescence with monoclonal PHM5 IgG on a cryostat section of normal human kidney. The antigen is localized to the glomerulus, where it outlines the visceral epithelial cells. $\times 450$. 


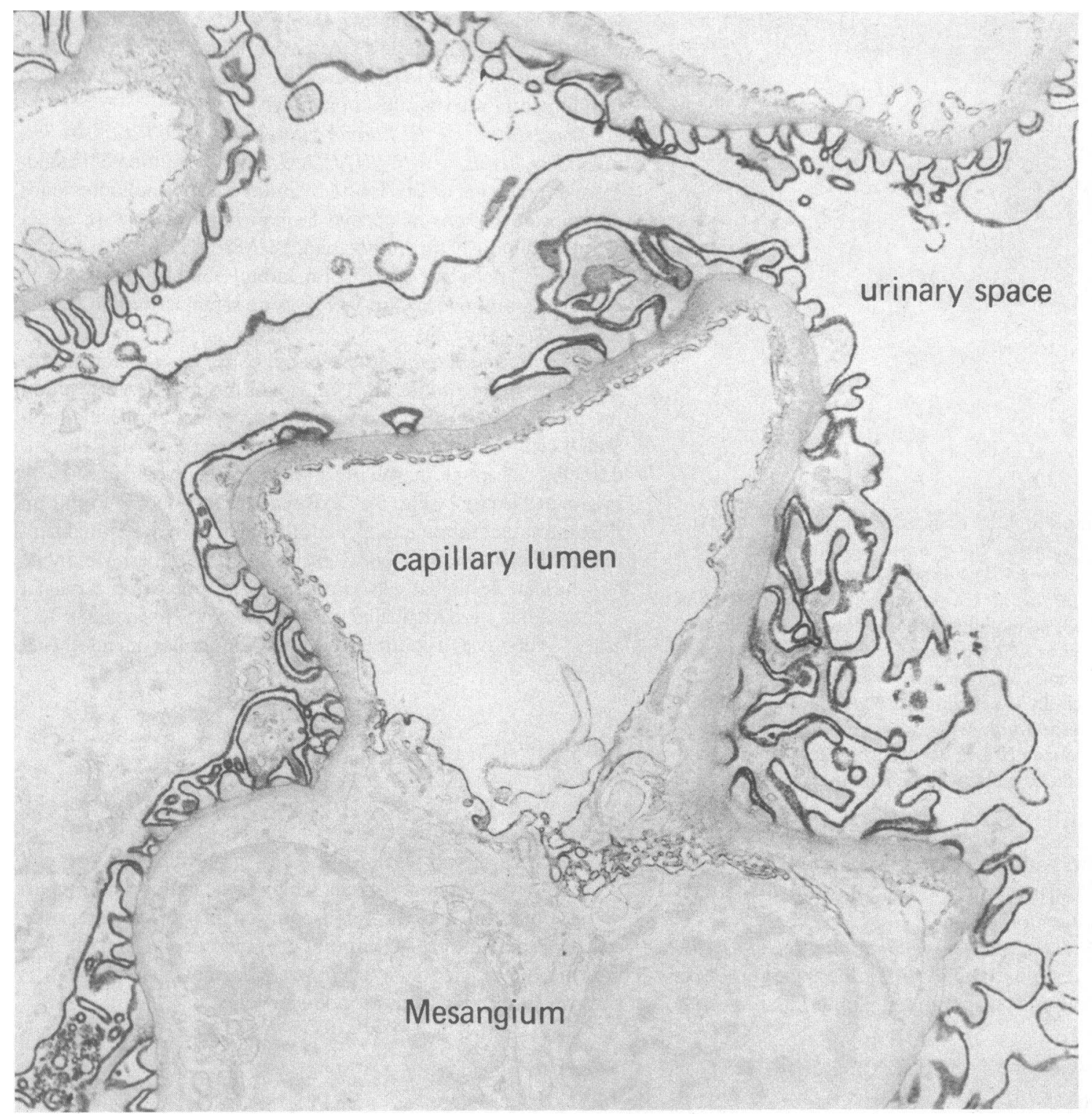

(5)

Figure 5. Localization of the human 165-170-kD sialoprotein by immunoelectron microscopy, using the immunoperoxidase method with monoclonal PHM5 IgG. The sialoprotein is concentrated at the surface of glomerular epithelial cells, and, in smaller amounts, also on endothelial cells. $\times 12,000$.

Several findings indicate that the human $165-170 \mathrm{kD}$ molecule is a sialoprotein, although currently there is not enough purified material available for a direct chemical analysis. The criteria for the sialylation of the $165-170-\mathrm{kD}$ protein are similar to those used for rat podocalyxin $(8,15)$ : The $165-170-\mathrm{kD}$ glycoprotein binds almost selectively ${ }^{125}$ I-WGA (which is known to bind also to sialic acid) (16). Accordingly, this affinity is abolished by neuraminidase digestion, by which binding sites for ${ }^{125}$ I-PNA appear, due to the exposure of penultimate galactose on oligosaccharides. The presence of sialic acid is further indicated by changes in electrophoretic mobility of the $170-\mathrm{kD}$ protein by digestion with neuraminidase. The appearance of a band with lower electrophoretic mobility could be due to partial loss of sialic acid which causes a decrease in the negative net charge of the molecule. A similar phenomenon has been observed in partially desialylated glycophorin (17), and in podocalyxin of puromycine nephrotic rats (18). The relative contents of sialic acid in the 165- and 170-kD molecules are not known. Because Stains All and ${ }^{125}$ I-WGA almost selectively stain the 165- and $170-\mathrm{kD}$ bands, it appears that this molecule is the most abundant sialoprotein in the human glomerulus.

Changes in the electrophoretic mobility of the 170-kD molecule by digestion with $N$-glycanase (which probably results in incomplete deglycosilation) indicates the presence of at least one $\mathrm{N}$-linked oligosaccharide chain. $\mathrm{N}$-linked oligosaccharide chains were also found in rat podocalyxin by digestion with endoglycosidase $F(18)$. Whether the human podocalyxin-like molecule contains O-linked oligosaccharides or not (as is the case in rat podocalyxin [18]) cannot be determined conclusively at present.

A major difference between rat podocalyxin and the human 


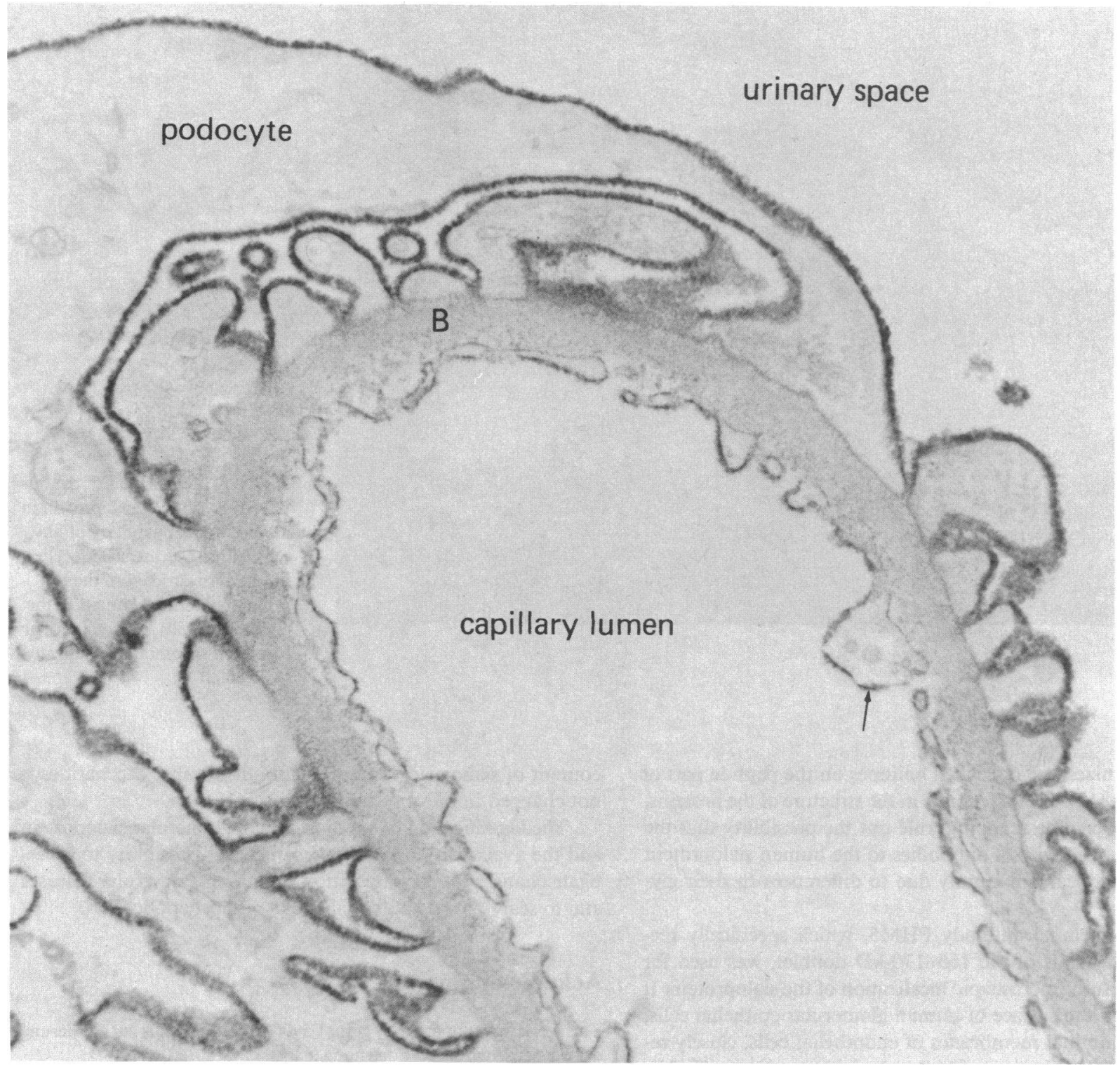

(6)

Figure 6. Localization of the human 165-170-kD sialoprotein as in Fig. 5. In this high power view it can be observed that podocalyxin is absent from the base of the podocytes's foot processes. Arrow, positive reaction on the surface of endothelial cells. $B$, glomerular basement membrane. $\times 62,000$.

glomerular sialoprotein is their mobility in SDS gels: whereas the rat molecule has an apparent $M_{\mathrm{r}}$ of $140 \mathrm{kD}$, its human counterpart is composed of a doublet of molecules with $M_{\mathrm{r}} \mathrm{s}$ of 165 and $170 \mathrm{kD}$. The 165 - and $170-\mathrm{kD}$ bands of the human protein are chemically closely related, as shown by their almost identical proteolytic peptide maps, and probably differ only in their glycosilation. Based on this structural homology, the split band on SDS gels can be attributed to a single molecule.

A further difference between the human sialoprotein and rat podocalyxin is shown by the dissimilarity of their peptide maps. This dissimilarity indicates little or no structural homology. A limitation on this conclusion is that peptide mapping was carried out only in one dimension and concentrated on the $80-\mathrm{kD}$ fragments; the other portion of the molecules might be homologous. However, these data, combined with the lack of cross reactivity of the rabbit anti-rat podocalyxin polyclonal antibody to the human protein, strongly suggest that these are substantially different molecules. There are several examples in other systems (e.g., the ankyrins from brain and erythrocytes) in which two molecules have similar functions but show different peptide maps (19).

Antibodies directed against the rat and human molecules do not cross react by immuneoverlaying and immunofluorescence. This indicates that the human and the rat molecules are also distinct in their antigenic structure. Previous data have indicated that the epitope for PHM5 monoclonal IgG is associated with the carbohydrate moiety because treatment with periodate of tissue sections abolished its binding (9). In contrast, the polyclonal rabbit anti-rat podocalyxin IgG binds also to extensively (but not completely) deglycosilated podocalyxin, which suggests 


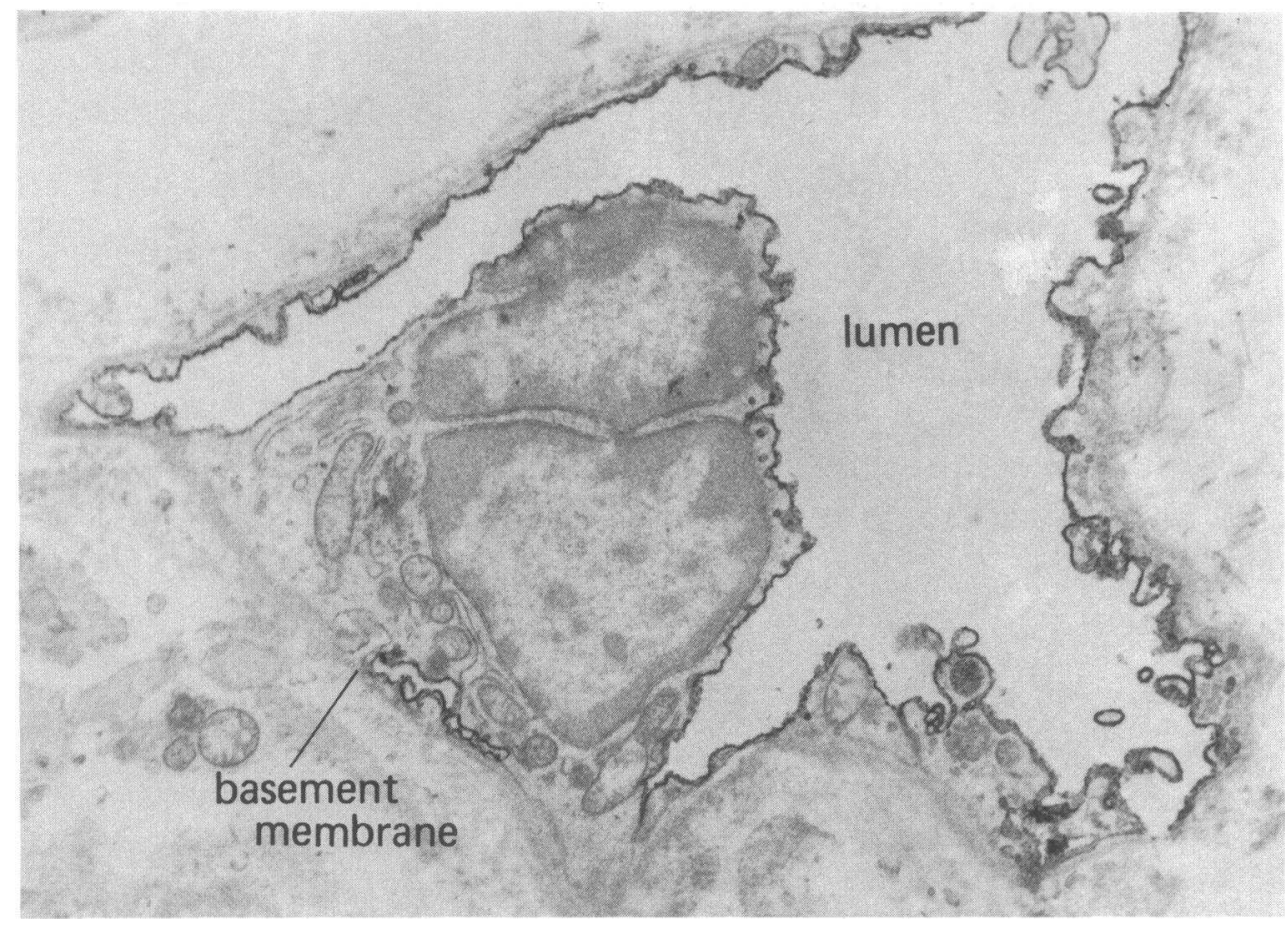

(7)
Figure 7. Localization of the human 165-170-kD sialoprotein in an intertubular capillary of human kidney cortex. The reaction product is restricted to the luminal membrane domain of the endothelial cells. The glomerular basement membrane is indicated. $\times 24,000$. that it recognizes one or several epitopes on the peptide part of the molecule (18). The differences in the structure of the proteins, as shown by peptide mapping, rule out the possibility that the lack of cross reactivity of antibodies to the human sialoprotein and to rat podocalyxin is only due to differences in their glycosilation.

The monoclonal antibody PHM5, which specifically recognizes both bands of the 165-170-kD doublet, was used for immunoelectron microscopic localization of the sialoprotein. It was found on the surface of human glomerular epithelial cells, and on the luminal membranes of endothelial cells, closely resembling the distribution of podocalyxin in rat tissue $(8,20)$. Recently, a protein called podoendin was described that shows a distribution similar, but not identical, to podocalyxin on the surfaces of rat glomerular epithelial and on endothelial cells (21). A major difference from podocalyxin, however, is that podoendin contains very little or no sialic acid, and that its apparent $M_{\mathrm{r}}$ is different $(65-\mathrm{kD})$. Thus, the sialoprotein described in this paper is different from podoendin.

In summary, the human sialoprotein and rat podocalyxin show several similarities, such as their staining properties in gels, their sialic acid-mediated binding of WGA, and their anatomical distribution. They differ, however, in their apparent $M_{\mathrm{r}}$ in SDS gels, in most of their proteolytic fragments in peptide maps, and in their antigenic structure. It is therefore quite possible that they are evolutionarily distinct proteins that have similar functions but no other relationship.

The glomerular epithelial polyanion has been of interest for a long time because staining by histochemical reactions was found to be reduced or abolished in children with minimal change nephrosis (6), and in rats that had been made nephrotic by injection of puromycin aminonucleoside (7). We recently found that rat podocalyxin suffers a selective reduction in its content of sialic acid while the amount of other saccharides is not changed in puromycine nephrosis (18).

The identification of a major human glomerular sialoprotein and the availability of antibodies open the possibility to investigate changes in its composition in human glomerular diseases and to search for its potential use in clinical application.

\section{Acknowledgments}

This work was supported by grant P5900 from the Fonds zur Förderung der Wissenschaftlichen Forschung.

\section{References}

1. Mohos, S. D., and L. Skoza. 1969. Glomerular sialoprotein. Science (Wash. DC). 164:1519-1521.

2. Jones, D. B. 1969. Mucosubstances of the glomerulus. Lab. Invest. 21:119-125.

3. Nolte, A., and M. Ohkuma. 1969. Elektronenmikroskopisch-histochemische Untersuchungen zur Darstellung saurerer Mukopolysaccharide und Sialinsäurehaltiger Glycoproteine in Nierenrinde und innerem Nierenmark der Ratte. Histochemie. 17:170-180.

4. Holthöfer, H., I. Virtanen, E. Petterson, T. Tornroth, O. Alfthan, E. Linder, and A. Miettinnen. 1981. Lectins as fluorescence microscopic markers for saccharides in the human kidney. Lab. Invest. 45:391-399.

5. Charest, P. H., and J. Roth. 1985. Localization of sialic acid in kidney glomeruli: regionalization in the podocyte plasma membrane and loss in experimental nephrosis. Proc. Natl. Acad. Sci. USA. 82:85088512.

6. Blau, E. B., and J. E. Haas. 1973. Glomerular sialic acid and proteinuria in human renal disease. Lab. Invest. 28:477-481.

7. Michael, A. F., E. Blau, and R. L. Vernier. 1970. Glomerular polyanion: alteration in aminonucleoside nephrosis. Lab. Invest. 23:649657. 
8. Kerjaschki, D., D. J. Sharkey, and M. G. Farquhar. 1984. Identification and characterization of podocalyxin - the major sialprotein of the renal glomerular epithelial cell. J. Cell Biol. 98:1591-1596.

9. Hancock, W. W., and R. C. Atkins. 1983. Monoclonal antibodies to human glomerular cells: a marker for glomerular epithelial cells Nephron. 33:83-90.

10. Hancock, W. W., N. Kraft, F. Clarke, and R. C. Atkins. 1984. Production of monoclonal antibodies to fibronectin, type IV collagen and other antigens of the human glomerulus. Pathology. 16:197-206.

11. Greenwood, F. C., W. M. Hunter, and J. S. Clover. 1891. The preparation of ${ }^{125}$ I-labeled growth hormone of high specific activity. $J$. Biochem. 89:114-126.

12. Cleveland, D. W., S. G. Fischer, M. W. Kirschner, and U. K. Laemmli. 1977. Peptide mapping by limited proteolysis in sodium dodecyl sulfate and analysis by gel electrophoresis. J. Biol. Chem. 252:402406.

13. Herrmann, H., and G. Wiche. 1983. Specific in situ phosphorylation of plectin in detergent-resistant cytoskeletons from cultured chinese hamster ovary cells. J. Biol. Chem. 258:14610-14618.

14. Kerjaschki, D., and M. G. Farquhar. 1983. Immunocytochemical localization of the Heymann nephritis antigen (Gp330) in glomerular epithelial cells of normal Lewis rats. J. Exp. Med. 157:667-686.
15. Green, M. R., and J. V. Pastewka. 1975. Identification of sialic acid rich glycoproteins on polyacrylamide gels. Anal. Biochem. 65:6672.

16. Peters, P. B., S. Ebisu, J. Goldstein, and M. Flashner. 1979. Interaction of wheat germ agglutinin with sialic acid. Biochemistry. 18: 5505-5511.

17. Gahmberg, C. G., and L. D. Anderson. 1982. Role of sialic acid in the mobility of membrane proteins containing O-linked oligosaccharides on polyacrylamide gel electrophoresis in sodium dodecyl sulfate. Eur. J. Biochem. 22:581-586.

18. Kerjaschki, D., A. T. Vernillo, and M. G. Farquhar. 1985. Reduced sialylation of podocalyxin - the major sialprotein of the rat kidney glomerulus-in aminonucleoside nephrosis. Am. J. Pathol. 118:343349.

19. Davis, J. Q., and V. Bennett. 1984. Brain ankyrin: purification of a 72,000 Mr spectrin-binding domain. J. Biol. Chem. 259:1874-1881.

20. Horvat, R., A. Hovorka, G. Dekan, H. Poczewski, and D. Kerjaschki. 1986. Endothelial cell membranes contain podocalyxin-the major sialoprotein of visceral glomerular epithelial cells. J. Cell Biol. 102:484-491.

21. Huang, T. W., and J. C. Langlois. 1985. Podoendin: a new cell surface protein of the podocyte and the endothelium. J. Exp. Med. 162: 245-267. 